\title{
The influence of the environment on a person's sexual orientation: intergenerational analysis in Russia
}

\author{
Alexander M. Rikel ${ }^{1, *}$ \\ ${ }^{1}$ Lomonosov Moscow State University, Mokhovaya St, 11/9, 125009, Moscow, Russia
}

\begin{abstract}
The psychological studies of the phenomenon of homosexuality is easier to find in European and American research. In this connection, the social-psychological specifics of representations towards homosexuality seems logical, as well as a valuable diversity of representations within society. Of particular interest is the study of this attitudes in the information society, where the media and social networks form bright, often polar points of view. In some previous papers it was shown that the $\mathrm{Z}$ Generation is described in terms of more tolerant position towards commonly segregated social groups. The purpose of this study was to reveal the representations about homosexuality among various generations of Russians. The methodological core of the research was the study of social representations (P. Vergesse method). The research methods implied the questionnaire aimed at figuring out representations about homosexuality and a modified variant of the RAHI test. Sample was N = 444 (residents of Russia, 16-65 y.o.). The hypotheses of the research were confirmed: an inverse relationship between belonging to a generational cohort and attitude towards homosexuality as normal was revealed. A significant difference between the $\mathrm{Z}$ Generation in tolerance of representations about homosexuality was shown. Some 'double standards' towards male and female homosexuality were distinguished. The basic notion of homosexuality as a interaction, based, on a sexual (not love-spiritual kind of relationship), was defined. Conclusions were drawn about the multidimensional influence of channels of mass communication on different generations.
\end{abstract}

\section{Introduction}

Homosexuality can be defined through any manifestation of sexual behavior and attraction to person of the same sex [1], through concomitant affective attachment [2], through a way of identification and self-identification [3].

The study of homosexuality is interesting in the context of the changing scientific consensus about its nature: at the end of the XIX century, this phenomenon was considered pathological, attempts to treat this 'disease' did not stop until the middle of the XX century and caused a stir in scientific and public discourse [4]. Homosexuality was persecuted not only in authoritarian, but also in 'Western' democratic regimes, where the media reported

\footnotetext{
* Corresponding author: a.m.rikel@gmail.com
} 
that the communists propagated homosexuality among American youth in order to contribute to its moral decay. Since the second half of the XXth century, the gradual legalization of same-sex relationships around the world has begun. In 1974, the APA recognized homosexuality as a 'model of sexual behavior', and in 1992, 'homosexuality' was excluded from the ICD. With the development of the trend towards the humanistic development of science and society, many psychological studies have become focused, on the contrary, on education, the study of mechanisms to counteract stigmatization, debunking destructive myths about homosexuality [5].

The political components of the regulation of attitudes to homosexuality in Russia made it possible to exclude 'Sodomy' from the Criminal Code only in 1996. At the same time, it is obvious that legal liberalization has caused an ambiguous impact on public sentiment: opinion polls in 2018-2019 show that the views of modern Russians towards the phenomenon of homosexuality are generally characterized by a negative attitude: $87 \%$ of respondents oppose the legalization of same-sex marriage, $35 \%$ of respondents said that they would react with hostility if they were told about their homosexual orientation, according to $5 \%$ of respondents, homosexuals should be 'eliminated'. At the same time, the cohort of people who demonstrate tolerance to this group is growing: $47 \%$ of respondents say that representatives of the LGBT community should enjoy the same rights as citizens of 'traditional' sexual orientation. Researchers call this indicator the highest in the last 15 years [6].

A striking factor influencing the diversity of ideas about social phenomena that polarize society is often the diversity of information channels. It seems obvious and repeatedly confirmed that the factor of belonging to the generation plays a decisive role in choosing the source of information: while the older generations $(\mathrm{X})$ are used to trust the $\mathrm{TV}$, the younger ones $(Z)$ prefer social networks $[7,8]$.

In the context of such a significant polarization, it is of interest to identify the views of individual social groups. An analysis of American studies shows that the factors of race (belonging to white or African Americans) [9], religion (identifying oneself as a believer or non-believer) [10] do not play such a significant role as belonging to a particular generation. At the same time, in a recent Russian large-scale study, religious respondents expressed a greater prejudice against homosexuals, more often negative attitudes were demonstrated by men, as well as heterosexuals who have never experienced romantic feelings for members of their own sex [11].

The study described here examines only the factor of belonging to a generation in the context of the formation of representations about homosexuality. Other factors are not analyzed. Generations are usually studied not only as representatives of different age groups, but also as social cohorts. Thus, according to the classical interpretation of K. Mannheim, a generation is understood as a community of people who experienced in the so-called formative years (the years of adolescence and youth) a unique historical, economic, political or technological experience that formed a special socio-psychological portrait for them [12]. This understanding of generation unites modern Russian and Western sociologists and social psychologists and allows us to put forward various author's classifications of generations based on the general principle of the social context that influences the formation of a generation [13-16]. One of the most popular media typologies of Howe and Strauss [17], despite its popular scientific nature, is often used in rigorous scientific research as the most common type of generation classification in Russia and abroad (in Russia, this theory was adapted in the early 2000 s by E. Shamis and V. Nikonov) [18]. The modern generations ' $X$ ' (born in 1963-1984), ' $Y$ ' (born in 1984-2000) and ' $Z$ ' (born in 2000 and further) differ significantly in their attitude to trends that are usually perceived as 'Western': the values of tolerance, cosmopolitanism, the perception of 'family' values, traditionalism, religiosity, etc. [13]. 
Most members of the X Gen did not always share Communist views of parents and older brothers and sisters, they became disillusioned with the war in Afghanistan and the so-called period of stagnation in the economy and politics; the ' $\mathrm{X}$ ' met 'Perestroika' being young people, many of them were happy to have the opportunity of 'westernization' of the social context. Gen Y is the first generation, born in the new Russia, and their childhood coincided with the promotion of individualistic values and cosmopolitanism, but due to the difficult period of the 1990s, the attitude to these values was not uniform [19]. Gen Z is sometimes referred to as the 'digital', 'networked', or 'I-generation' [20], thus describing the significant immersion of this generation in Internet interaction. In Russia, this generation is often described as individualistic, striving for hedonism and freedom [18, 21].

The methodology for separating age, cohort, and social context factors in intergenerational studies is extremely complex [18]. As possible methodological solutions, it is recommended to resort to longitudinal studies, time-consuming meta-analyses or the socalled APC analysis (Age-Period-Cohort Analysis), which requires significant timeconsuming research, that does not guarantee the high quality of the obtained result [22]. In this regard, most intergenerational studies ' $\sin$ ' by the lack of a solution to this problem. In the context of studying representations about the phenomenon of homosexuality, the radically changing social context makes this task (separating the factor of age and the factor of cultural and historical context) practically unsolvable, which does not reduce the value of studying these representations.

A recent American study [23] shows that tolerance towards homosexuals increases inversely with age: young people are more tolerant of LGBT people due to their exposure to modern culture and media that broadcast these ideals. In an earlier work [24], the author also confirms that young people in the United States are more tolerant of homosexual people, but considers this through the prism of feminist 'optics', considering that the negative perception of homosexual persons is associated with a patriarchal foundation: gay men are considered insufficiently masculine, and lesbian women do not fulfill their 'traditional' female role. Young people are more tolerant of the role of women in society and, accordingly, are more likely to be tolerant of homosexuals. The association of homophobia with the level of sexism, a tendency to traditional gender roles and increased masculinity in men is confirmed in other studies [25-26]. J. Twenge easily finds an explanation for the greater tolerance to LGBT people in the American Z Gen compared to Y Gen: the period of adolescence of the latter fell during the years of President B. Clinton, who actually banned same-sex marriage in the United States, while generation ' $Z$ ' completely caught the liberalization LGBT laws and relevant trends in mass media [27].

Many Russian-language sociological, philosophical and cultural publications contain, rather, the authors 'value declarations' 'for' or 'against' homosexuality as a phenomenon [2829] or describe it in the context of cultural and historical context [30] and do not contribute to the analysis of the views of modern Russian society. Some studies present a sociological cross-section of the granularity of representations. Thus, T.Petinova and colleagues in their study $(\mathrm{N}=211)$ demonstrated a low level of tolerance (no higher than 14-16\%) among Samara city youth (university students), as well as contradictory views (the coexistence of the awareness that all people are different and have the right to express their sexuality, with the idea of a possible 'homosexual revolution' in Russia, which needs to be rebuffed) [31]. A study of the perception of homosexuality by Murmansk city students $(\mathrm{N}=176)$ showed similar contradictory trends: $47 \%$ attributed this phenomenon to pathology, and $30 \%$ - to the norm; $31 \%$ - have a negative attitude towards homosexual families, and 56\% - are neutral. In this survey, different attitudes towards gays and lesbians were also recorded. In a larger threestage study by $\mathrm{O}$. Gulevich and colleagues $(\mathrm{N}=1007)$, a high rate of homophobia was also identified, as well as factors of perception of threats from the homosexual community: a threat to individuals, morality, society, Russian culture, and the rights of heterosexuals [11]. 
The contradictory trends in these attitudes should be interpreted not only as a result of a complicated history of the problem, but also as a growing intergenerational gap in information consuming: different web resources preffered by $\mathrm{Z}$ Gen offer broader range of views than TV does [7].

\section{Materials and Methods}

The problem. Studies of representations about homosexuality in Russia do not set the task of analyzing their structure, as well as little affect the generational analysis of these ideas, which is extremely important when talking about this popular topic in public discourse. The aim is to identify social representations about homosexuals and homosexuality among representatives of different generations of modern Russians. Object of research is homosexuality. The subject of the study is social representations about homosexuality among representatives of different generations. Hypotheses are: 1. Representatives of the younger $\mathrm{Z}$ Gen demonstrate views characterized by a more positive attitude towards homosexuality than other generations studied (' $\mathrm{X}$ ' and ' $\mathrm{Y}$ '). 2. Views characterized by the most negative attitude towards homosexuals in the study sample are shared by X Gen. The methodological complex consisted of: (1) The author's complex questionnaire for identifying social representations in different generations, which includes the following blocks: (A) Demographic characteristics of the respondents; (B) The image of homosexual people and representations about homosexuality and homosexuals: (a) representations about the concept of homosexuality (for example, 'What do you think is homosexuality?', 'Please write 3 words that come to your mind when you hear the word 'homosexuality'?'); (b) personal attitudes towards different types of homosexuality (for example, 'How can you describe your attitude towards homosexuals?', 'Which homosexuality do you think is more acceptable in our society?'); (c) ideas about the attitude towards homosexuals in society (for example, 'How can you describe the attitude towards homosexuals in society?'); (d) ideas about the privacy or publicity of homosexuality (for example, 'Should homosexuals hide their orientation, and why?'); (e) ideas about the prevalence of homosexuality (for example, 'Which homosexuality do you think is more common?'); (f) Projective questions (for example, 'What do you think if a gay person was an animal, what kind of animal?'). (C) A modified Bogardus scale of social distance, which allows us to assess the degree of desired proximity / remoteness of a particular social group (in this case, homosexuals); (2) The Russian Questionnaire on Attitudes towards Homosexuals (RAHI) [11].

The study of social representations (concept by S. Moscovici) took place in the logic of structural analysis (method by P. Vergess). The author's questionnaire underwent preliminary pilot testing and subsequent adjustment, and the modified Bogardus scale was tested until the internal consistency indicators were achieved.

Sample. The sample $(\mathrm{N}=444$ people, from 16 to 65 years old) was formed by a 'snowball method. The sample contains 170 representatives of generation ' $Z$ ' (16-22 years, mean age - 20 years), 181 - generation ' $\mathrm{Y}$ ' (25-34 years, mean age -30 years), 93 - generation ' $\mathrm{X}$ ' (37-63 years, mean age -44 years). The sample has no significant shifts in place of residence (266-residents of large cities (starts with 100,000 residents), 178-residents of small cities), level of education (80-secondary or specialized secondary education, 97-incomplete higher education, 277-higher education). The sample was biased by gender, which should not have significantly affected the quality of the data obtained (112 men, 332 women). The absolute majority of respondents identified themselves as heterosexuals, the factor of belonging to the LGBT community was analyzed separately.

The results were processed in MS Excel (version 15.28) and SPSS (version 23.0). We used the tools of (1) content analysis (to analyze answers to open questions), (2) descriptive statistics; (3) correlation statistics (T-test to determine significant differences in attitudes to 
homosexuality between samples; Pearson correlation analysis to compare the results of content analysis); (4) the methods of P. Vergess for identifying the structure of social representations; (5) the standardized test norms of the RAHI method [11].

\section{Results}

Here are the results (see Table 1) of the RAHI questionnaire, which identifies the overall level of homophobia in the sample. The results are presented for each of the studied generations.

Table 1. Averaged values of homophobia indicators for each of the generations (RAHI questionnaire).

\begin{tabular}{|l|c|c|c|c|c|}
\hline & Z Gen & Y Gen & X Gen & Mean & Std. Dev. \\
\hline Culture Threat & $1.93 / 5$ & $2.01 / 5$ & $2.17 / 5$ & $1.97 / 5$ & 1.14 \\
\hline Individuals Threat & $1.53 / 5$ & $1.75 / 5$ & $2.07 / 5$ & $1.60 / 5$ & 0.89 \\
\hline Society Threat & $1.83 / 5$ & $1.95 / 5$ & $2.25 / 5$ & $1.82 / 5$ & 1.13 \\
\hline $\begin{array}{l}\text { Heterosexual's Rights } \\
\text { Threat Strategy of }\end{array}$ & $2.28 / 5$ & $2.55 / 5$ & $3 / 5$ & $2.77 / 5$ & 1.34 \\
\hline $\begin{array}{l}\text { The of } \\
\text { Punishment }\end{array}$ & $1.27 / 5$ & $1.33 / 5$ & $1.35 / 5$ & $1.22 / 5$ & 0.64 \\
\hline $\begin{array}{l}\text { The Strategy of } \\
\text { Treatment }\end{array}$ & $2.1 / 5$ & $2.46 / 5$ & $2.47 / 5$ & $1.89 / 5$ & 0.97 \\
\hline $\begin{array}{l}\text { The Strategy of } \\
\text { Dicrimination }\end{array}$ & $1.78 / 5$ & $1.96 / 5$ & $2.18 / 5$ & $1.82 / 5$ & 0.88 \\
\hline Total
\end{tabular}

It is seen from Table 1 that the representations of the surveyed sample as a whole are not characterized by a negative connotation in relation to homosexual people. Similarly, representatives of each generation do not experience homophobia separately, and representatives of generation ' $\mathrm{Z}$ ' experience significantly less homophobia than representatives of generation ' $\mathrm{X}$ ' $(\mathrm{F}=3,306 ; \mathrm{p}=0.01)$. No differences were found between the other generations. At the same time, most of the respondents expressed concerns about the possible threat to the rights of heterosexuals (this result is the most significant for all three generations). Similarly, all three generations were the least likely to agree on the need to punish homosexuals for their orientation. At the level of the entire sample, a more positive perception of homosexuals was confirmed in residents of large cities compared to small ones $(\mathrm{F}=12.059 ; \mathrm{p}=0.01)$, in women compared to men $(\mathrm{F}=2.74 ; \mathrm{p}=0.05)$, as well as in people who consider themselves to be LGBT people $(\mathrm{F}=94.07 ; \mathrm{p}=0.00)$ (which seems logical). There were no significant differences in the level of homophobia among the respondents with different levels of education. The results on the modified Bogardus scale of social distancing also show high scores, that is, the predominant absence of prejudice against homosexuals (see Table 2). Thus, the average score (5.41) shows that the majority of respondents agree with 5 out of 7 statements of the scale, that is, they agree with the statement that they are ready to 'live in the same household' and 'be friends with a homosexual', but do not agree to 'become his relative'. There were no statistically significant differences between the generations in the framework of this scaling.

Table 2. Averaged values of indicators of social distance from the group of homosexuals for each of the generations (modified Bogardus scale).

\begin{tabular}{|l|c|c|c|}
\hline & Z Gen & Y Gen & X Gen \\
\hline Bogardus Scale Scores & $5.6 / 7$ & $5.38 / 7$ & $5.26 / 7$. \\
\hline
\end{tabular}


When answering the questions 'Estimate your attitude towards homosexuals' and 'Estimate the attitude of society towards homosexuals' (five-point Likert scales), there is a trend in all three cohorts to view personal attitudes as more positive (see Table 3). In all three generational cohorts, the personal attitude towards homosexuals is more likely to be positive, while the attitude of society is more likely to be negative. At the level of the trend, there is a perception of a more tolerant attitude of representatives of generation $\mathrm{Z}$ compared to generation $\mathrm{X}$.

Table 3. Averaged values of personal attitude and evaluation of society's attitude to homosexuals in different generations (Likert scales).

\begin{tabular}{|l|c|c|c|}
\hline & Z Gen & Y Gen & X Gen \\
\hline Society Attitude & $2.38 / 5$ & $2.17 / 5$ & $2.29 / 5$ \\
\hline Personal Attitude & $3.92 / 5$ & $3.57 / 5$ & $3.26 / 5$ \\
\hline
\end{tabular}

When answering the question 'Should society change its attitude to homosexuals, and how?', a categorical grid was developed, consisting of basic categories-strategies of 'Discrimination', 'Protection', 'Treatment', 'Distancing', 'Acceptance'. Generation X much more often than other cohorts sees fit 'Discrimination' (lower rights) homosexuals (13,5\%), and generation $\mathrm{Y}$ and $\mathrm{Z}$ in contrast, often claim they need their Protection (20,4\% and 24.8\%, respectively). Generation $\mathrm{X}$ is also more likely than $\mathrm{Y}$ and $\mathrm{Z}$ to believe that homosexuals should hide their sexual orientation $(F=13,432 ; p=0,00)$. Generation $Z$ is less likely than other generations to oppose the active demonstration of their sexual orientation by homosexuals $(\mathrm{F}=6,422 ; \mathrm{p}=0.00)$, while all three generations consider it unsafe to openly declare it (48.9\% of respondents' responses). The majority of respondents consider female and male homosexuality to be equally common (see Table 4), but there are significantly more respondents in Generation $\mathrm{X}$ and $\mathrm{Y}$ who consider male homosexuality to be more common than female homosexuality.

Table 4. Representations about the prevalence of male and female homosexuality in different generations (\%).

\begin{tabular}{|l|c|c|c|}
\hline & Z Gen & Y Gen & X Gen \\
\hline Male & 18.82 & 30.39 & 43.01 \\
\hline Female & 17.65 & 14.36 & 4.30 \\
\hline Same & 63.53 & 55.25 & 52.69 \\
\hline
\end{tabular}

When answering the clarifying question about the acceptability of a particular homosexuality, the differences between the generational cohorts are again vivid: $Z$ and Y's believe that female homosexuality is more acceptable in Russian society, while generation $X$ is of the opinion that both homosexualities are unacceptable in Russian society, but they consider female homosexuality more acceptable than male homosexuality.

To identify the structure of social representations about homosexuality, a content analysis of the answers to the questions 'What is homosexuality?' and 'Please write down the three words that come to your mind when you hear the word 'homosexuality'?' was carried out. The results show that homosexuality is most often defined through 'Intimate relationships' (41.5\%), mainly 'Sexual orientation' (10.4\%). The older generation (X) more often than Y's and Z's in their answers resort to explaining the nature of homosexuality through 'Mental deviation' $(14.6 \%)$ or 'Promiscuity' $(6.4 \%)$ (Pearson's $k=0.887 ; p=0.01)$. In the associative series with homosexuality in the generation $\mathrm{Y}$ and $\mathrm{Z}$, the most frequent mention of male homosexuality ( $13.1 \%$ and $10.9 \%$, respectively), and the least frequent mention of female homosexuality ( $4.2 \%$ and $4 \%$, respectively). Generation Z mentions the LGBT notion more often than representatives of other generations $(15.6 \%)(\mathrm{k}=0.823 ; \mathrm{p}=0.01)$. Y's and Z's more often then X's talk about positive characteristics of homosexuality $(7.8 \%, 7.6 \%$ and $15.2 \%)(\mathrm{k}=0.8623 ; \mathrm{p}=0.01)$. Associations explaining the nature of homosexuality show 
that generation $\mathrm{Z}$ tends to explain homosexuality through a person's independent choice $(3.8 \%)$, and generation $\mathrm{X}$ more often explains homosexuality as a perversion and disease (4.8\%). Generation Y takes an intermediate position, sharing both opinions.

The structure of social representations about homosexuality in each generation was calculated separately according to the method of P. Vergess, which determines the core and periphery depending on two variables: the average rank of the association and the frequency of its mention by respondents. The structure of the associative field within the views is described lower.

In the core area of ideas about homosexuality in X Gen split into the categories: 'gay', 'perversion', 'man'. Less common, but often occupying the first positions in the line of associations: 'orientation', 'various obscene characteristics'. They often meet, but less often occupy the first positions: 'LGBT', 'lesbian',' rainbow','sex'. The remaining categories fall into the second peripheral system, which is not considered as a potential zone of change.

In the core area of ideas about homosexuality in generation ' $\mathrm{Y}$ 'fall into the categories: 'gay', 'love', 'man'. Less common, but often occupying the first positions in the line of associations: 'perversion', 'deviation', 'freedom'. Often meet, but less often occupy the first positions: 'various obscene characteristics', 'lesbian', 'relationships', 'rainbow', 'sex'. The remaining categories split into the second peripheral system, which is not considered as a potential zone of change. In the core area of ideas about homosexuality in generation ' $\mathrm{Z}$ 'split into the categories: 'gay', 'love', 'man', 'norm', 'orientation'. Less common, but often occupying the first positions in the line of associations: 'wrestling', 'boys'. Often meet, but less often occupy the first positions: 'lesbian', 'LGBT', 'freedom', 'rainbow', 'sex'. The remaining categories split into the second peripheral system, which is not considered as a potential zone of change.

The analysis of the differences between the nuclear and peripheral systems in the associative characteristics of 'men of homosexual orientation' shows that generations ' $Z$ ' and ' $Y$ ' mention associations from the category 'Love', and generation ' $Z$ '- associations from the category 'Friend' - in the first peripheral system. There are no such categories in the associations of generation ' $\mathrm{X}$ '.

The analysis of the differences between the nuclear and peripheral systems in the associative characteristics of 'women of homosexual orientation' shows that generation ' $\mathrm{X}$ ' has the characteristics of strangeness and masculinity in the core of representations that are not found in other generations. At the same time, even in the first peripheral system of associations, ' $\mathrm{X}$ ' does not mention the love that both younger generations do. Generation ' $\mathrm{Z}$ ' adds to the first peripheral system a category of 'Ordinariness' that is not found in other generations.

The final block of the questionnaire was the projective questions 'What do you think if a gay person was an animal, then what?' and 'What do you think if a lesbian was an animal, then what?'. These questions, of course, are additional and do not claim to be strictly meaningful validity of the data, but they help to complement the existing image of homosexuals. Generation $\mathrm{Z}$ is more likely to associate a homosexual man with a feline ('cat'). Generation Y has a higher percentage of associations in the 'Wild Cat' category ('panther', 'leopard', etc.). Generation X prefers two categories, such as 'Bright birds '('peacock', 'parrot') and 'Metaphorical non-intelligent animals' ('ram', 'goat'). Most representatives of all generations see a homosexual woman as either a 'Cat' or a representative of 'Wild Cats'

\section{Discussion}

The results obtained in the study, at first glance, may seem revolutionary in terms of comparison with the data obtained in early sociological surveys $[6,11,29,31]$. Thus, the views identified using the RAHI questionnaire and the modified Bogardus scale show more 
positive views of homosexuals than in the mentioned studies. A more detailed statistical analysis allows us to conclude that this result is more 'soft' in relation to homosexuals due to the 'contribution' of representatives of generation ' $Z$ ' among the respondents, as well as due to the factor of place of residence (large cities with a population of more than 100,000 people). The exclusion of representatives of the younger generation, residents of large cities and, in fact, representatives of the LGBT community from the analysis allows us to obtain a result close to the previously identified data [11]. At the same time, it is impossible not to note the socio-psychological cognitive distortion characteristic of all three generations: respondents on average consider their own attitude to homosexuality much milder than the attitude of society: similar effects can be observed in various studies of stereotyping and stigmatization, for example, in the study of infidelity [32].

At the same time, generation ' $Z$ ' demonstrates the idea of homosexuality as a more normative phenomenon: the average indicators of their personal attitude towards homosexuals are positive, and their idea of the attitude of people around them is close to positive, which partly reproduces the idea of a more tolerant attitude among urban students. They consider it more correct to 'protect' homosexuals from aggressive attitudes, and they do not object to the active demonstration of their sexual orientation by homosexuals. ' $Z$ ' is more knowledgeable in terminology and more often uses scientific and legal terms related to LGBT topics, which indicates their more neutral and prepared level of perception. They are more likely than other generations to talk about the 'independent choice of a person', arguing about the causes of homosexuality as a phenomenon, although many early foreign studies have found that a positive attitude towards homosexuals, on the contrary, is more often associated with the idea of innate sexual orientation [33-35]. ' $Z$ ' is the only generation that avoids obscene statements about homosexuals (in the core and 1st peripheral systems of representations), as well as adding the idea of 'normativity' to the core of social representations.

Generation $\mathrm{X}$, on the contrary, in the sample surveyed in this study, demonstrates the highest level of homophobic perception (although it retains conditionally 'positive' views on the Bogardus scale). ' $\mathrm{X}$ ' more often than other generational cohorts believe that homosexuals should be 'discriminated' in one form or another (lowered in civil rights compared to heterosexuals), that they should hide their sexual orientation. They are more likely to interpret homosexuality as a pathology or as the influence of widespread immoral public attitudes, more often express negative or obscene offensive judgments in a conversation about homosexuality. This is the only generation in which the core of social ideas is the idea of 'perversion'. The inverse relationship between perceptions of the normality of homosexuality and the age of respondents was demonstrated in earlier Western studies [23]. It should be noted that in the 'core' of the structure of representations in this generation, there are characteristics of an intimate or sexual relationship, excluding love and spiritual relationships. This fact can be interpreted from the position of the deep rootedness in the everyday consciousness of the sexual basis in the formation of homosexual relations (it is no coincidence that in Russian and English 'sexual orientation' and 'homosexuality' have a lexical basis that goes back to the sexual sphere). Even at the level of projective questions, the association of ' $\mathrm{X}$ ' is distinguished by a more socially undesirable and demonstrative character ('sheep', 'goats', 'peacocks', etc.).

Generation ' $\mathrm{Y}$ ' occupies the so-called sandwich generation position 'between' cohorts both in chronology and in the essence of representations about homosexuals. Their average indicators of homophobia occupy an intermediate position between ' $\mathrm{X}$ ' and ' $\mathrm{Z}$ '; in the general absence of denial of homosexuality, they, like ' $X$ ', rather believe that homosexuality should be hidden, but at the same time, like ' $Z$ ', more often reproduce positive or neutral associations to homosexuality. It is no coincidence that in the peripheral system of ideas there 
are conflicting ideas about the 'Freedom' and 'Perversion' of homosexuals, which generally fits into similar Western trends in this generation [27].

The social representations of all three generations are associated with the data obtained in early studies on the values of generational cohorts, according to which the younger generations are characterized by a greater expression of the values of cosmopolitanism, individualism and freedom (and, as a result, tolerance and tolerance) [19, 21].

The irrational ideas about the greater permissibility of female homosexuality, which are characteristic of all three generations, are curious. A possible reason for this logic of 'double standards' lies in the patriarchal nature of society, which prescribes stricter standards of 'correct male' behavior; in the perception of male homosexual behavior as weaker, in deliberate propaganda aimed against male homosexuality. In this context, female homosexuality does not cause negative obscene associations in any of the generations, it is associated with pornographic products, and in the most conservative older generation, ' $\mathrm{X}$ ' causes more ideas about its 'strangeness' than about negativity. At the same time, generation ' $\mathrm{Z}$ ' is also more liberal in its ideas about female homosexuality, associating it with 'love' and some romantic experiences ('kisses', etc.). 'Feline' homosexual associations of generations ' $\mathrm{Z}$ ' and ' $\mathrm{Y}$ ' confirm this trend: the respondents associate cats with something freedom-loving and not subject to the usual norms, but at the same time not repulsive.

\section{Conclusion}

1. The social representations of Russians about homosexuality are not characterized by a negative attitude, while the main contribution to these views is made by young residents of large cities.

2. At the same time, studies of representations about homosexuality do not allow to carry out the analysis of deep emotions and experiences, and the conclusion about the inhomophobia of Russian society can be considered premature.

3. The views of the younger $Z$ Gen are characterized by a more positive perception of homosexuality, compared to the $\mathrm{X}$ and $\mathrm{y}$ Gens, and the most negative perception of homosexuals in the study sample is present in the generation ' $\mathrm{X}$ '. This conclusion allows us to confirm hypotheses 1 and 2 .

4. The Information era with its' broad range of sources of mass communication can be seen as one of the main explanatory mechanisms (and at the same time instruments) of generational gap in representations about homosexuality.

5. Russians evaluate female homosexuality more positively than male, while maintaining a certain level of homophobia towards manifestations of homosexuality in general.

\section{Possible limitations of the conclusions}

1. The lack of gender equality of the sample may serve as a limitation and a basis for further expansion of research, however, the available sample allowed us to draw valid conclusions, and a detailed analysis of the sex factor was not part of this work.

2. The use of quantitative research methodology does not always mean a thorough analysis of socially sensitive subjects of study (in particular, homosexuality). Further research in line with the qualitative approach (in-depth interviews, projective techniques, etc.) could expand the data obtained. At the same time, the concept of social representations (S. Moscovici) assumes its study using the tools of quantitative methodology, which allows us to speak about the validity of the work carried out. 


\section{References}

1. S. Jain, S. Silva, The Professional Counselor: Research and Practice 1(3), 208-221 (2011) DOI: 10.15241/sjj.1.3.208

2. D.A. Knight, Clinical Men's Health E-Book: Evidence in Practice (Elsevier Health Sciences, 2008) DOI:10.1016/B978-141603000-3.10029-2

3. R.E. Wickham, R. Gutierrez, B.L. Giordano et al., Assessment 1073191119893010 (2019) https://doi.org/10.1177/1073191119893010

4. M. King, A. Bartlett, The British Journal of Psychiatry 175(2), 106-113 (1999) DOI: 10.1192/bjp.175.2.106

5. G.M. Herek, Perspectives on Psychological Science 5(6), 693-699 (2010) DOI: 10.1177/1745691610388770

6. Levada Tsentr, For equal rights for LGBT people. Interview (2019) https:/www.levada.ru/2019/05/23/pochti-polovina-rossiyan-vystupila-za-ravnyeprava-dlya-geev/

7. S.B. Dust, M. Gerhardt, D. Hebbalalu et al., The Journal of Social Psychology 159(2), 153-169 (2019) DOI: 10.1080/00224545.2019.1570903

8. S. Taipale, Information, Communication \& Society 19(1), 80-94 (2016) DOI: 10.1080/1369118X.2015.1093528

9. G.M. Herek, J. Gillis, C. Cogan, Journal of Counseling Psychology 56(1), 32-43 (2009) DOI: $10.1037 / \mathrm{a} 0014672$

10. W. Rowatt, J. Kelly, B. Lamartina et al., Journal for The Scientific Study of Religion 45 (2006) DOI: 10.1111/j.1468-5906.2006.00314.x

11. O. Gulevich, E. Osin, N. Isaenko, L. Brainis, Psychology. HSE Journal 1(13), 79-110 (2016) DOI: 10.17323/1813-8918-2016-1-79-110

12. K. Mannheim, Essays on the sociology of knowledge (London, New York, Routledge, 1997)

13. V. Pishchik, A. Belousova, L. Ryumshina, Proceedings 10th International Conference on Education and New Learning Technologies, 1782-1786 (2018) doi: 10.21125/edulearn.2018.0524

14. C. Gilleard, P. Higgs, Contexts of Ageing: Class, cohort and community (Polity Press, Cambridge, 2005)

15. E.J. Helsper, R. Eynon, British Educational Research Journal 36(3), 503-520 (2010) doi: 10.1080/01411920902989227

16. J.M. Twenge, S.M. Campbell, Perspectives on Psychological Science 5(1), 81-88 (2010) DOI: $10.1177 / 1745691609357015$

17. H. Howe, W. Strauss, R.J. Matson, Millennials rising: The next great generation (Vintage, New York, 2000)

18. A. Rikel', Social Psychology and Society 2(10), 9-18 (2019) doi:10.17759/sps.2019100202

19. N. Gerard, Leadership in Health Services 32(3), 364-386 (2019) https://doi.org/10.1108/LHS-01-2018-0004

20. M. Van Volkom, J. Stapley, J. Malter, Educational Gerontology 39(10), 729-740 (2013) DOI: $10.1080 / 03601277.2012 .756322$

21. V. Pishchik, M. Postnikova, E3S Web Conf., Innovative Technologies in Science and Education (ITSE-2020) 210 (2020) https://doi.org/10.1051/e3sconf/202021022002 
22. L. Chauvel, F. Smits, European Societies 17(2), 242-278 (2015) DOI: 10.1080/14616696.2015.1006133

23. P.M. Ayoub, J. Garretson, Comparative Political Studies 50(8), 1055-1085 (2017) DOI: $10.1177 / 0010414016666836$

24. E. Decoo, Changing attitudes toward homosexuality in the United States from 1977 to 2012. All Theses and Dissertations (2019) https://scholarsarchive.byu.edu/etd/4091

25. M.J. Brown, E. Henriquez, Journal of Homosexuality 58, 462 - 475 (2011) https://doi.org/10.1080/00918369.2011.555664

26. K.L. Collier, H.M.W. Bos, T.G.M. Sandfort, Journal of adolescence 35(4), 899-907 (2012) doi:10.1016/j.adolescence.2011.12.010

27. J.M. Twenge, R.A. Sherman, B.E. Wells, Arch Sex Behav. Journal, 1-8 (2016) doi:10.1007/s10508-016-0798-z

28. N. Chudinova, Sotsial'nye i gumanitarnye nauki: teoriya i praktika 1, 483-487 (2017)

29. G. Horne, M. Maroney, E. Zagryazhskaya, J. Koven. Psychology in Russia: State of the art 10(2), 21-34 (2017) DOI:10.11621/PIR.2017.0202

30. V. Kortunov, I. Lapshin, N. Zorina et al., Modern Research of Social Problems 9, 152175 (2015) DOI: 10.12731/2218-7405-2015-9-11

31. T. Petinova, V. Gridina, Education and problems of development of society 2(6), 64-71 (2018)

32. R. Ueda, K. Yanagisawa, H. Ashida, N. Abe, Cognitive, Affective, \& Behavioral Neuroscience 17(6), 1210-1220 (2017) DOI: 10.3758/s13415-017-0543-7

33. M. Bettinsoli, A. Suppes, J.L. Napier, Social Psychological and Personality Science 11(5), 697-708 (2020) doi:10.1177/1948550619887785

34. G.A. Boysen, D.L. Vogel, Sex Roles: A Journal of Research 57(9-10), 755-762 (2007) https://doi.org/10.1007/s11199-007-9256-7

35. N. Haslam, B. Bastian, P. Bain et al., Group Processes \& Intergroup Relations 9(1), 6376 (2005) https://doi.org/10.1177/1368430206059861 